\title{
Nas entrelinhas da narrativa: vozes de mulheres imigrantes
}

\author{
NÚNCIA SANTORO DE CONSTANTINO*
}

\begin{abstract}
Resumo: O presente texto propõe reflexão sobre História Oral e sobre mulheres imigrantes na cidade de Porto Alegre. Pretendo continuar tal reflexão, dialogando com personagens das pesquisas que desenvolvo, pessoas que colaboram à reconstrução de processos históricos, com seus depoimentos. As reflexões que pretendo desenvolver dizem respeito, sobretudo, à memória e à subjetividade e faz-se necessário retomar algumas questões teóricas fundamentais.
\end{abstract}

Abstract: The present text proposes a reflection about Oral History and about immigrant women in the city of Porto Alegre. I intend to continue this reflection, dialoguing with the "characters" of the research I develop - people who collaborate to the reconstruction of historical processes with their testimony. These reflections have to do, mainly, with memory and subjectivity, and it is necessary to retake some theoretical basic questions.

Palavras-chave: História Oral. Narrativa. Imigração.

Key words: Oral history. Narrative. Immigration.

Sabemos que a História Oral revitalizou-se; esta é uma discussão praticamente encerrada nos meios acadêmicos. Também sabemos que, se a História Oral revitalizou-se, foi principalmente porque, na França, o chamado Grupo dos Anais propôs um novo tipo de História, decorrente de outra concepção da ciência histórica e de sua produção.

Mais que uma renovação temática, aconteceu mudança radical na relação do historiador com o passado. O objeto da ciência histórica deixou de ser simplesmente alcançado pelas fontes, para ser construído pelo historiador, a partir das demandas do seu presente. A importância do seu trabalho passou a ser entendida como resultado das perguntas que este

Doutora em História Social, docente e pesquisadora do Programa de Pós-Graduação em História-PUCRS.

Estudos Ibero-Americanos. PUCRS, v. XXXII, n. 1, p. 63-73, junho 2006 
historiador faz ao passado. $\mathrm{O}$ documento continuou sendo a matériaprima imprescindível, fosse ou não um documento escrito, mas passou a ter valor na dependência da qualidade das indagações propostas a este passado.

Desenvolveu-se também uma história mais ampla, incluindo todas as atividades humanas, atingindo outras áreas de conhecimento, já de início a lingüística, a psicanálise, passando pelos estudos sobre a memória, incluindo os biológicos.

Nesta história mais ampla, são passíveis de inclusão todas as ações de todos os homens, inclusive das pessoas comuns, aquelas que deixam poucos traços nos arquivos instituídos. Com o tempo, tornou-se necessário ouvir, prestar atenção na palavra dos outros.

Importante lembrar que, nos anos setenta do século passado, as Ciências Humanas e Sociais começaram a utilizar com maestria o microscópio, juntamente com o telescópio que há muito era utilizado. Foi aceito o uso da análise de tendências específicas juntamente às tendências gerais. Le Roy Ladurie, Carlo Levi e Ginzburg são bons exemplos desta transformação metodológica. E o último apontando os indícios como chaves para o conhecimento de realidades mais amplas.

A narrativa histórica foi retornando com força, surgindo a ênfase na apreensão sociológica e psicológica do acontecido no passado, que precisa ser progressivamente dissecado. Por isso, menciona-se o conceito de estranhamento ou distanciamento como instrumento teórico com alto nível de precisão.

Ginzburg justifica a necessidade de estranhamento ao historiador, afirmando que se trata de antídoto eficaz contra aquilo que sempre foi dito, que repetimos por hábito. ${ }^{1}$ Antídoto que permite encontrar indícios, pequenas partes passadas desapercebidas; que permite diagnosticar alguns sintomas, como pensou Freud.

E a subjetividade entra na discussão. O historiador passa a ser responsável pela história e a historiografia representa o seu momento de lembrar, sopesadas algumas armadilhas da memória. $\mathrm{O}$ historiador recria o fato histórico, precisa reconstruir da melhor forma possível. Com História Oral estará, além do mais, criando as fontes, com a ajuda de quem vivenciou e narrou.

Pois bem, no espaço que me destinam estou refletindo sobre os desvãos da narrativa, sobre os elementos da subjetividade que compõem esta narrativa do outro. Tratando-se de assunto árido no âmbito da abstração, pretendo intercalar com a empiria da pesquisa que desenvolvo através da metodologia da História Oral.

1 GINZBURG, Carlo. Occhiaci di legno: nove riflesisoni sulla distanza. Milano: Feltrinelli, 1998, p. 33-34. 
Estou ouvindo mulheres imigrantes, desenvolvendo projeto em rede internacional, tendo como parceira a professora Chiara Vangelista, da Universidade de Turim. Desejamos que a mulher imigrante conte seu percurso, seja uma mediadora entre duas realidades distintas, aquela que deixou e aquela que encontrou. Ouvem-se mulheres, porque estão mais dispostas a falar, porque vivem intensamente o dia-a-dia e para que seja considerado o papel da mulher na imigração que, entre nós, foi sempre irritantemente um assunto masculino.

Preciso saber dessas mulheres como vivenciaram o fenômeno da imigração e como olharam a cidade em que chegaram, provenientes da Europa. Mulheres imigrantes contam sobre a cidade brasileira, sublinhando aquilo que foi o exótico. Olharam melhor e mais atentamente o desconhecido, aquilo que escapava para os da terra. Já está mencionado aqui o conceito de estranhamento como ferramenta ao historiador.

Procuro dialogar com polonesas, com mulheres judias que saíram, respectivamente, da Alemanha e da Polônia, no início da década de 1930; com italianas que partiram do extremo norte,do extremo sul da península e da Sicília. ${ }^{2}$

E aqui já vou ingressando superficialmente com a temática da imigração, justificada hoje como objeto da História pelas novas indagações que estão sendo propostas, temática relacionada ao meu projeto individual de pesquisa. Não estou por demais preocupada em registrar que o Imperador D.Pedro II estimulou a imigração italiana ou que as mentes progressistas dos republicanos tantos benefícios trouxeram ao Brasil, abrindo portas aos estrangeiros. Trato principalmente de contextualizar países, destacando fatores de expulsão, de analisar o contexto do país para onde se emigrou, de saber quem emigrou.

A imigração é um fenômeno de massas, mas é também e, em primeiro lugar, um deslocamento de diferentes pessoas em diferentes tempos e espaços, qualificados em muitos sentidos, isto é, social, econômica, política e culturalmente. E é sempre uma viagem, uma longa viagem aquela que realiza o imigrante, com seus três momentos, que variam de duração, isto é, partida, trânsito, chegada, segundo Richard Leed. ${ }^{3}$ Sistematizo dados nestes momentos, que transformo em categorias. As mulheres contam sobre a partida, o trânsito e a chegada, para que seja possível conhecer algo de suas trajetórias.

2 O estudo foi realizado a partir de depoimentos transcritos, em fitas magnéticas e em CDs, arquivados no Centro de História Oral do Programa de Pós-Graduação em História da PUCRS. Tratando-se de ensaio teórico, em certos trechos, tratou-se de omitir nomes, preservando a identidade das depoentes.

3 LEED, Eric. La mente del viaggiatore: dall'Odissea al turismo globale. Bolonha: Il Mulino, 1992, p. 41-138. 
Das suas narrativas posso inferir que há partidas gestadas por décadas, que há gente que espera crescer para emigrar, porque, em algumas regiões, emigrar é praticamente a única saída. Percebo que há gente que é compelida a partir em decorrência de fatores pontuais, resultantes de contextos específicos.

Os pais de Hana trataram de emigrar diante dos avanços do nazismo; saíram da Polônia em 1930. Lá eram comerciantes de tecidos e viviam muito bem, negociando nas feiras de muitas cidades próximas de Zulomil, até que começaram a perseguir os judeus. O pai partiu primeiro $e$, depois de sete anos, conseguiu trazer a família. Esperou a mulher e os filhos no cais, trazia na mão barras de chocolate que ofereceu às crianças.

Da Polônia, emigrou a família de Wanda, em 1928, escapando da extrema pobreza. A pouca terra que possuíam não garantia o sustento do casal e dos dois filhos. Jan, Marjana e o casal de filhos deixaram todos os parentes que nunca mais encontraram. Instalaram-se no bairro Navegantes, residindo junto às fábricas onde começaram a trabalhar.

Chiara nasceu na aldeia alpina de Costalta, em 1920. Seu pai era mestre-pedreiro e, uma vez por ano, ia trabalhar na Áustria. Com a mãe e os irmãos, Chiara trabalhava na horta e cuidava dos animais domésticos. Lembra seu paese: "um lugar lindo, lindíssimo uma jóia, a bonita igreja de onde se avistava muitas outras aldeias". Tem saudades da infância naquele bonito lugar, acompanhando o pai à caça, deslizando na montanha coberta de neve, em rápido trenó. Depois da guerra, casou com um veterinário. Na difícil conjuntura, o marido aceitou um emprego no Brasil. Fez a longa travessia do oceano e avistou finalmente o Rio de Janeiro, porta principal de entrada do país em que iria viver: "É a cidade mais linda do mundo". A partir de 1950, Chiara viveria em Porto Alegre, onde chegou com dois filhos pequenos. A cidade impressionou-a: "muito desenvolvida, parecia Milão".

Conta Valeria, proveniente dos arredores de Trieste. Sofrera a guerra, trabalhou muito, casou, embarcou para o Brasil, em 1951, já com um filho pequeno. Crescera perto de Trieste e vivenciou duramente o conflito mundial a partir dos dez anos, porque pertencia à uma família de "partigiani". Com a mãe viúva e com a irmã, passou algum tempo na prisão, enquanto o irmão encontrava-se foragido na montanha, esperando a chegada dos americanos. Mas os exércitos aliados tardavam e o irmão foi capturado e morto pelos alemães. Enquanto a família chorava, velando o seu morto, da janela avistava-se a longa fila de prisioneiros alemães que passava diante da casa de Valéria, pois, finalmente, a guerra acabava. Casou-se muito jovem e emigrava pouco tempo depois, com um filho pequeno. O marido encontrara emprego no Brasil, em empresa multinacional que produzia massas alimentícias. 
Os pais de Ruth, sofrendo a perseguição dirigida aos judeus, abandonaram Frankfurt com algum dinheiro e duas filhas. No carnaval de 1934, chegaram a Porto Alegre e, quinze dias depois, o pai encontrava trabalho como alfaiate. "Tudo era tão diverso, precário; aqui ainda se cozinhava com lenha, não havia a modernidade alemã! ... Era preciso ir de um lugar ao outro sempre a pé, subindo e descendo montes... Não tinha mais minha bicicleta, deixada no outro lado do mundo".

O noivo de Concetta emigrou. A moça casou por procuração em Morano Calabro; com 23 anos, viajou para encontrar o marido no Brasil, em 1950. Viajou na companhia de uma tia e encontrou outra Morano em Porto Alegre, com centenas de amigos, parentes, conhecidos, todos falando o seu dialeto. Passou a residir com os tios do marido, com quem este trabalhava.

Maria veio chamada pelo irmão imigrante, que conseguiu pagar as passagens da família que ficara na Itália. Como sabia costurar, encontrou seu primeiro emprego em camisaria, conseguindo juntar algum dinheiro, estabeleceu-se por conta própria, produzindo confecções infantis. Ao chegar, decepcionou-se com as condições de moradia e com a vizinhança que encontrou na periferia da cidade, em vila popular. Mas lembra com saudade de Porto Alegre naqueles anos cinqüenta, dos bailes na Sociedade Italiana, onde fez os primeiros amigos no outro lado do mundo.

Francesca veio atrás do marido e do filho mais velho, que há muito estavam em Porto Alegre. Não conhecia a lingua nem os costumes, nada encontrava que pudesse lembrar o seu sistema de trabalho doméstico. "Como iria fazer o almoço no outro dia?" O dinheiro era pouco, logo também as filhas precisariam trabalhar. Sua primeira casa era feia, de táboas, muito pobre e desconfortável, em rua sem calçamento. Naquela casa passaram mais frio do que na Itália, onde havia neve, mas as casas eram de pedra e o fogo estava sempre aceso na cozinha. Depois, mudouse para o Bairro IAPI, onde conseguiram comprar um apartamento, e ali começou a fazer as amizades que sempre a acompanharam no Brasil.

As emigrantes partiram por diferentes razões e em diferentes condições. Transitaram por maior ou menor tempo. Construíam novas identidades e aprenderam a viver na terra a que estavam destinadas.

Concetta reencontrou centenas de parentes em Porto Alegre, onde nasceram suas filhas. Nos primeiros tempos, não saía, porque "não sabia falar, e isso era ruim, muito ruim mesmo".

Ruth nada via do que imaginara do Brasil, com ninguém conseguia falar, porque só conhecia a língua alemã. Faltava o conforto que desfrutava em Frankfurt. Freqüentava o colégio e ajudava o pai na alfaiataria, pregando botões e falando alemão com seus próprios botões, porque amigas custou a arranjar. 
Quando Chiara, com a familia, fixou-se em Porto Alegre, sentiu-se em Milão; desfrutou a cidade moderna, ainda que detestasse a comida: sempre feijão e arroz.

Valeria, com o marido e duas crianças pequenas, foi residir no bairro industrial, onde começavam a construir uma fábrica de massas. Havia umidade e a casa estava cheia de baratas enormes. Precisava ir à padaria com um dicionário, para pedir o desejado.

Hana detestou Porto Alegre, sem parentes, sem amigas. Chorou para voltar à casa, na Polônia, onde perseguiam os judeus, como ela.

Francesca e Maria defrontaram-se com uma realidade muito diferente da esperada; uma pequena casa de madeira em vila popular e um trabalho árduo e mal remunerado.

Entretanto, quase sempre, independente do tempo empregado, dá-se a chegada na terra da diáspora.

Chiara precisou de auxílio doméstico, pois a família aumentava depressa no Brasil. Conseguiu uma moça da região colonial italiana, que lhe "ensinou a ser brasileira".

Concetta diz que "acostumou-se mesmo quando veio a primeira filha... já conseguia comunicar-se” e, quando precisou ajudá-la nas lições de casa, conhecia razoavelmente a língua portuguesa. Se algumas vezes teve vontade de voltar a Morano, a vontade logo passou. Depois de vinte anos, retornou ao seu paese, onde tudo estava moderno, desenvolvido; todos possuíam carros, bonitas casas. Sobrinhos e primos já nem falavam o dialeto, e Concetta passou a ser chamada de "prima americana".

Valeria entendeu que precisava fazer amizades. Suas crianças brincavam na pracinha e foi ali que encontrou as primeiras amigas brasileiras. Sublinha que as suas amigas são brasileiras, "aquelas dos primeiros e dificeis tempos".

As coisas ficaram melhores para Ruth, quando começaram a chegar outros judeus alemães. Logo fundaram uma sinagoga e desenvolveuse uma vida social entre imigrantes. Ruth foi conhecendo moças e rapazes, houve namoros. Casou com Carlos, em 1941, e tiveram três filhas. Voltou uma vez a Frankfurt, atendendo a convite do governo alemão. Não encontrou nada, nem ninguém. Diz ter compreendido muito bem onde estava seu mundo.

Hana trabalhou para um alfaiate e depois para uma modista, onde aprendeu a cortar e a costurar. Freqüentou a Sinagoga da Rua Henrique Dias, dançou nos bailes da Sociedade Israelita. Enamorou-se de Isaac e casou logo depois de conhecê-lo, os filhos nasceram porto-alegrenses, em chalé alugado no bairro Bonfim. Seu marido trabalhou como marceneiro para patrões, até conseguir abrir sua fábrica de móveis.

Francesca adaptou-se logo diante do progresso da família. Uma filha dona-de-casa, casada com "brasileiro", outra filha solteira, comer- 
ciante; o filho mais velho também comerciante, outro publicitário e um terceiro médico. Nunca aprendeu a falar português, mas, quando vai à Itália, quer logo voltar, porque sente saudades de sua família brasileira.

Maria conseguiu importante espaço no ramo de confeções, em pouco tempo de Brasil. Trabalhou muito e comprou imóveis que aluga. Teve condições de ajudar toda a familia, conseguiu financiar os estudos do irmão menor que é médico.

Para o historiador da imigração, não se trata de analisar uma massa sem rosto, mas pessoas que se deslocam, motivadas por inúmeras razões, construindo novas identidades, em busca do que acreditam ser melhor, com arrojada iniciativa.

Continuo minha reflexão sobre História Oral e busco inspiração em Vico. ${ }^{4}$ Aqueles que criam ou fazem alguma coisa podem entendê-la melhor do que observadores, porque os homens constroem sua própria história. $^{5}$

Já estou bem longe da historiografia ranqueana, tomo distância da camisa-de-força cartesiana. Historiadores que buscam ou produzem fontes orais são aqueles que consideram a História como ciência em permanente construção, distanciada de verdades demonstráveis, invariáveis. No século XXI, a História é concebida como resultado de um esforço criador. E História Oral pressupõe conjugação de esforços criadores: depoente e pesquisador.

A par dos números relacionados aos fluxos humanos, às quantidades de dinheiro ou de mercadorias que cruzam o oceano, a par da detalhada análise dos fatores de expulsão e de atração, a par dos conflitos, ou dos consensos, preciso ver muitos rostos e ouvir muitas vozes, quando estudo imigração. Muitos rostos além daqueles que deram certo e cujos retratos estão emoldurados nas fábricas, nos bancos, nas grandes casas comerciais. Também preciso olhar para além dos rostos daqueles infelizes que não deram certo e cujas fotografias estão estampadas nas páginas policiais. Opressores e oprimidos não esgotam o assunto. Preciso ver e ouvir muito para reconstruir, com todas as deficiências que uma reconstrução supõe, o complexo e multifacetado fenômeno da imigração. São as vozes que me devolvem os rostos de pessoas comuns.

É preciso entender o funcionamento desta memória que armazena lembranças. Iván Izquierdo me responde por que costumamos lembrar em detalhe fatos antigos. Muitas vezes, porque tais fatos foram acompanhados de forte carga emocional. As memórias emocionais são gravadas em

4 VICO, Gianbattista. La scienza nuova. Milano: Rizzoli, 1994.

5 Ver, CONSTANTINO, Nuncia Santoro de. Sobre a atualidade de Vico. Histórica: Revista da Associação dos Pós-Graduandos em História-PUCRS. Porto Alegre, n. 4, 2000. 
momento de hiperatividade dos sistemas hormonais e neuro-hormonais. Além disso, para os velhos, há um tempo melhor para lembrar. Tempo em que havia uma vida pela frente, em que os amigos estavam vivos, em que não se padecia de bronquite ou de reumatismo. Ainda em Izquierdo, entendo porque temos a tendência de cancelar fatos desagradáveis, envolvendo dor, vergonha, humilhação. Utilizamos mecanismos como a repressão, descrito por Freud. O esquecimento do ruim pode ajudar a tocar a vida, neutraliza a depressão: nenhum sobrevivente de campo de concentração poderia voltar à vida se não fosse capaz de esquecer. Perdemos por esquecimento a maior parte de nossas memórias, a maioria das que restam atenuamos por meio da repressão ou da extinção. Nossa cognição, portanto, está composta basicamente por fragmentos da memória; peçam a alguém que conte sua infância e o fará em meia-hora. ${ }^{6}$

O conceito de memória é fundamental; em nosso caso, melhor dizer "memórias", porque são memórias que recolhemos em depoimentos orais. E memórias são narrações de quem vivenciou processos sócioculturais, enquanto memória, no singular, pode ser simplesmente a capacidade de reter fatos, idéias, impressões e retransmiti-las, através de diferentes suportes, como a escrita ou a voz.

Há diferentes categorias de memória. Há uma memória individual, relacionada à trajetória daquela pessoa que narra; os estudos de Henri Bergson nos ajudam a entendê-la, sobretudo se somados aos estudos de Freud. Através destes autores, compreende-se que a infância do indivíduo é importante na constituição desta memória, que irá censurar manifestações da memória coletiva. Então, é reconhecida a memória coletiva que transmite fatos ou aspectos culturais que têm maior significado a determinado grupo; esta categoria fundamenta-se nos estudos de Maurice Halbwachs, que sintomaticamente pertenceu ao Grupo dos Anais e que afirmou lembrarmos sob a moldura de um quadro social. A memória coletiva acabou sendo magistralmente descrita por Pierra Nora, cuja leitura faz parte do cotidiano dos historiadores.

Além de várias categorias de memória, ela será definida sob diferentes enfoques. Para a psicanálise, a memória é um campo no qual as significações feitas por alguém articulam-se em linha de continuidade, a partir das experiências vividas ou imaginadas; mas esta linha pode estar interrompida em alguns pontos pela ação de processos defensivos, os mecanismos de defesa, como a repressão, a negação, a racionalização, a projeção, também relacionados com a auto-representação. Todos esses conceitos fazem parte do domínio público e não é preciso ter formação médica com especialização em psicanálise para empregá-los. Lembra-se que não eram médicos os integrantes do grupo de Freud.

6 IZQUIERDO, Ivan. Questões sobre a memória. São Leopoldo: Editora Unisinos, 2004. 
Na verdade, memórias esquecidas podem estar reprimidas; a essência da repressão está em afastar algo do consciente, mantendo-o no inconsciente.

Hana nada conta de sua aldeia natal, na Polônia, de onde saíra com 13 anos; contudo registra que morreram em campos de concentração todos os parentes que lá ficaram. Depois de duas sessões de depoimento telefona, muito cedo, na manhã de um sábado. Precisava conversar porque "quase não dormira, lembrava de tantas coisas, era como se caminhasse nas ruas de Zulomil".

$\mathrm{Na}$ condição de historiadora, ajudo Hana a cavar, trazer à superficie aquilo que estava submerso.

Outro mecanismo de defesa é a negação. Algo que perturba o ego e que não é aceito na consciência. Os adultos tendem a fantasiar acontecimentos, ou mesmo "lembrar" aquilo que nunca aconteceu. Mais freqüente ainda é lembrar incorretamente dos fatos como forma de negação.

$X$. diz que revoltou-se contra o preconceito quando sua amiga Suely era barrada nos bailes; diz o motivo à baixa voz, referindo-se à vizinha falecida: era mulata.

Y. afirma ter uma raiz fortissima com seu paese; lá todos a procuram; há muita harmonia nas pequenas cidades italianas, todos se ajudam, não é como em Roma ou Milão. Fazem festa, quando ela chega e quando sai. Momentos depois, lamentará ter sido prejudicada na distribuição de uma herança pelos parentes italianos.

Outro mecanismo é a racionalização: processo de encontrar motivos lógicos, aceitáveis, para ações inaceitáveis.

$X$. chora o marido morto e resume todos os sacrificios em comum para criar os filhos. Ainda de preto, como as antigas viúvas, narra a dificil vida que levava, mesmo quando "ficaram bem de vida" no Brasil. Porque o marido gostava de mulheres, passava noites fora. Mas é assim na Itália, todos os homens de lá são assim; era bom pai, bom marido, nunca deixou faltar nada em casa.

Quanto à autorepresentação, precisamos considerar que as pessoas desejam apresentar-se com coerência, porque nem sempre foram coerentes. Amadureceram, mudaram, mas apresentam-se ao outro como se tivessem sido sempre assim. Trata-se da moldura do presente, como ensina Halbwachs.

Lembro Fraser $^{7}$, quando diz que a autorepresentação é expressada por estereótipos e mitos. Tratando-se do tema imigração, os estereótipos mais freqüentes são a mulher paciente, a mulher generosa, a mulher avançada, a mãe abnegada, o comerciante honesto, o pai trabalhador, o

7 FRASER, Ronald. História oral, história social. Historia Social. Valencia: Instituto de História Social, n. 17, outono 1993, p. 131-139. 
menino pobre e trabalhador, a filha dedicada, a mãe exemplar, o imigrante incansável, trabalhador modelo. Tais estereótipos são fenômenos culturais e, por isso, interiorizados, vividos como naturais.

Além do mais, Fraser sublinha que precisamos considerar as diferentes formas de narrar dos nossos depoentes, visto que privilegiam distintos gêneros literários. E cita os três principais modelos narrativos, a partir de um estudo de Chanfrault-Duchet. Tais modelos representam empréstimos de formas literárias disseminadas na tradição oral, na literatura, nas séries de TV. Quem deseja comunicar escolhe um gênero, ou ainda emprega gêneros combinados, de acordo com as posturas individuais diante deste ou daquele assunto. Os gêneros literários, portanto não são excludentes e também se transformam ao longo do tempo, quando predominantes, porque as pessoas também evoluem culturalmente. Então, a forma de narrar já pode vir a ser um interessante objeto de pesquisa histórica. $^{8}$

"Sou uma pessoa dividida, quero estar lá e quando estou lá quero estar aqui! Uma pessoa que emigra é dividida, nunca pode ser completamente feliz". Chiara pauta-se pela novelística, é dramática na sua autorepresentação. Fatalista é Concetta, que se adaptou, porque não havia outro jeito.

Maria diz que quem trabalha consegue vencer, como ela venceu; chora o sobrinho jovem falecido recentemente, busca consolo religioso, considera-se realizada; com seu trabalho formou médico o irmão. A sua é uma narrativa épica, com final feliz.

Valeria pensa que sempre esteve bem, porque soube adaptar-se. Freqüentava o açougue e a padaria com o dicionário na mão, aprendeu a comer feijão com arroz, matou insetos com o chinelo, ficou amiga de toda a vizinhança; em Porto Alegre, estão seus afetos e desafetos. Picaresca, Valéria ajusta-se, contorna, faz concessões e ri de sí mesma.

As depoentes lembram, refazem trajetórias, reconstroem processos sob ângulos inusitados. Destacam de imediato o exótico, como a desempenhar o papel de estranhas que delas se espera.

A menina alemã Ruth aprendeu a falar português e a subir as ladeiras da cidade, sentindo falta do conforto de Frankfurt. Imagem eloqüente é aquela de Hana, chorando no meio do pátio, desejando voltar para $\mathrm{Zu}$ lomil, onde as colegas de aula a desprezavam por ser judia. Até o dia em que também chegou. Porque um dia todas estas mulheres chegaram.

Com um olhar carregado de "presente", as depoentes se narram. Foi-lhes dado um momento para reconstruir o próprio passado. Dificilmente o imigrante se conta, dificilmente conta de si mesmo como tal. Através da oralidade posso devolver à imigrante o direito de narrar-se.

8 Marie-Françoise CHANFRAULT-DUCHET, apud FRASER, op. cit., p. 136-138. 
Independente de modelos, os depoimentos registrados são ricos de indícios que remetem ao cotidiano dos imigrantes e de suas famílias, ao trabalho que desenvolveram, à cidade européia que ficou para trás, à cidade brasileira que se transformou e que é lembrada pelo olhar desacostumado e distante daquela que foi uma estrangeira. Complexidade do fenômeno da imigração, não mais um contingente sem rosto.

Preciso agora tecer; fazer um texto histórico, contar um processo em que pessoas se deslocaram de um mundo para outro. Preciso ler nas entrelinhas das narrativas para enriquecê-lo. É indiscutível que Chiara, Valeria, Concetta, Wanda, Hana, Francesca, Maria ou Ruth ajudam a compor este texto sobre a imigração no Brasil, porque conhecem efetivamente o assunto. 